Bryant University

Bryant Digital Repository

Management Department Journal Articles

Management Faculty Publications and

Research

$1-2010$

\title{
Practitioner Perceptions of the A3 Method for Process Improvement in Health Care
}

John K. Visich

Bryant University

Angela M. Wicks

Bryant University

Faiza Zalila

University of Houston-Clear Lake

Follow this and additional works at: https://digitalcommons.bryant.edu/manjou

\section{Recommended Citation}

Decision Sciences Journal of Innovative Education, volume 8 issue 1, 2010, pp. 191-213.

This Article is brought to you for free and open access by the Management Faculty Publications and Research at Bryant Digital Repository. It has been accepted for inclusion in Management Department Journal Articles by an authorized administrator of Bryant Digital Repository. For more information, please contact dcommons@bryant.edu. 


\title{
Practitioner Perceptions of the A3 Method for Process Improvement in Health Care \\ John K. Visich, Bryant University \\ Angela M. Wicks, Bryant University \\ Faiza Zalila, University of Houston Clear Lake
}

\begin{abstract}
The focus of this paper is to present students' perceptions of the recently developed A3 method, a structured problem solving approach based on lean concepts and tools that have been adapted to the health care environment. The students were all employees of a large health care provider and were enrolled in a customized health care executive MBA Program. Each student was required to complete an individual A3 Project in order to improve a process at the department for which they worked. At the end of the semester the students presented their A3 projects to their peers who voted on the best projects. A survey measuring perceptions of the A3 method for problem solving in health care was administered and from it we present propositions for A3 implementation. These propositions are applicable both to health care practitioners and to academic researchers.
\end{abstract}

Key Words: A3 Method, Health Care, Active Learning, Process Improvement, Lean Systems 


\section{Introduction}

Health care organizations are under increasing pressure to find ways to manage their operations and processes more efficiently and effectively. The health care environment is dramatically changing and these organizations must find ways to become more innovative, to lower costs, and to increase patient satisfaction. These are daunting challenges that can be addressed by focusing on process change under the overarching umbrella of strategic planning aimed at achieving performance excellence. This paper focuses on pedagogy developed to address how health care organizations can achieve process improvement by using A3 techniques to eliminate waste in health care (Jimmerson, 2007). Students in a customized health care executive MBA (EMBA) Program were required to complete individual A3 Projects to improve operational processes in which they were directly involved. An integrated approach to total quality management was developed and supported by the use of quality tools, lean concepts and A3 problem solving for health care techniques.

\section{Challenges and Driving Forces in Health Care}

In no other industry has performance excellence become more critical than in health care. The industry has always been unique but is now facing several challenging issues including increasing costs, declining patient satisfaction, a critical nursing shortage, a lack of technological innovation, and a need to improve patient outcomes. Innovative services must be introduced (Carmen et al., 1996; Naman and Slevin, 1993). Rapidly changing markets, shifts in demand and customer expectations, and changes in technology, particularly in the area of information technology are drivers of change in the industry (Abernethy and Lillis, 2001; Carmen et al., 1996, and Bouwens and Abernethy, 2000). Health care is also seeing changes in demand 
(Carmen et al., 1996; Slater and Olson, 2000), which is forcing expansion of services offered (Abernethy and Lillis, 2001). Hospitals have had to adapt to unique implementation challenges: medical staff relations and quality of care are important attributes of hospital performance that can be difficult to measure, interpret, and compare with other organizations. And, the professional autonomy of physicians and the importance of long-term outcomes are both aspects of health care that have few analogs in other industries. Hospitals are facing the need to lower costs and improve patient satisfaction to remain sustainable.

Many of these challenges can be addressed by implementing processes to identify and eliminate waste, a major cause of high health care costs. Jimmerson (2007) adapted the Toyota Production System definitions to create the following seven categories of waste (muda) in health care: confusion, motion, waiting, processing, inventory, defects, and over-production. See the questionnaire in Appendix A for definitions of the seven mudas of health care. While waste reduction can result in reduced cycle times and improvement to process flows, many of the defined types of health care waste can lead to adverse events, perhaps the most onerous of all health care costs.

The Institute of Medicine defines an adverse event as "an injury caused by medical management rather than by the underlying disease or condition of the patient" (Crane and Crane, 2006, p. 3). Errors that cause an adverse event usually are drug-related but also include diagnostic errors, equipment failure, infections, blood transfusion-related injuries, and misinterpretation of medical orders (Crane and Crane, 2006). According to residents, the most common causes for medical errors are overwork, inadequate supervision, and handoff problems (Jagsi et al., 2005). Other contributory factors include lack of communication among and between all levels of the health care organization (Tang and Lansky, 2005), lack of or inadequate 
training for technology (Menachemi et al., 2006; Wicks et al., 2006), and lack of participatory decision-making by patients (Tang and Lansky, 2005).

According to the Institute of Medicine an estimated 44,000-98,000 patients die from medical errors each year in the United States. Using the low estimate value, hospital errors are the eighth leading cause of death in America, killing more people than breast cancer, traffic accidents or AIDS (Crane and Crane, 2006). And, it is estimated that medical errors cost the Medicare program more than $\$ 8.8$ billion annually (Business Wire, 2008).

\section{Process Improvement Literature in Health Care}

Various theories have been introduced to address health care waste and the resulting death rates and costs. Kohn et al. (2000) found that health care organizations use a systems approach to promote patient safety, reduce medical errors, and increase patient satisfaction. But the authors stated that health care organizations are "decades behind...in terms of creating safer systems" (p. 61) and believe that standards must be established together with processes to determine "systemic causes and consequences" (p. 382). Bliemel and Hassanein (2004) thought that health care systems should adopt re-engineering methodologies to reduce medical errors. In 2001, the Institute of Medicine requested a \$1 billion innovation fund to improve communication and change information technology systems (Relman, 2001). The report also recommended that the Department of Health and Human Services and the Agency for Healthcare Research and Quality develop processes to track process improvements. The 2007 American College of Physician Executives Quality of Care Survey found that physician respondents utilized a variety of quality programs as their primary approach to improve quality. The most common approach was Six Sigma (18.5\%), followed by Lean Processes (13.3\%) and vendor provided proprietary 
products $(12.2 \%)$. Other programs, including homegrown methods, were used by $26.7 \%$ and, alarmingly, $29.2 \%$ of the respondents reported that no one program is used as a primary method to improve quality (Martin, 2007). In this section we discuss the top two approaches, Six Sigma and Lean Processes, and their applications in the health care environment.

\section{Six Sigma}

The Six Sigma methodology was developed by Motorola Inc. in the United States in the late 1980s as a way to reduce defects in manufacturing processes (Nonthaleerak and Hendry, 2006). However, it was not until General Electric former CEO Jack Welch embraced Six Sigma in the mid 90's as a companywide quality and process improvement methodology that it became popular. The widely published notable success achieved by GE measured by high ROI and significant reduction in costs and increased customers' satisfaction convinced other companies to adopt this much acclaimed methodology.

The first known application of Six Sigma to the health care industry dates back to 1988 whereby Commonwealth Health Corporation (CHC), under the patronage of GE, launched a successful Six Sigma initiative becoming the Six Sigma pioneer in health care industry (Sehwail and DeYong, 2003; Feng and Manuel 2008). It was not until around the year 2000 that Six Sigma started to spread to the health care industry (Black and Revere, 2006). Some of the published results of health care applications include the successful implementation of Six Sigma in Charleston Area Medical Center, West Virginia, in an effort to reduce surgical equipment inventory costs (Simmons, 2002). Mount Carmel Health, Ohio, used Six Sigma to redefine their billing standards, and realized a decrease in the amount of bad debt that was previously written off (Lazarus and Butler, 2001). At Scottsdale Healthcare, Arizona, Six Sigma initiatives reduced 
patient transfer time from the emergency department, creating increased capacity for that department (Lazarus and Stamps, 2002). Similarly, Virtua Health, New Jersey, was able to improve patient satisfaction and reduce the length of stay for its congestive heart failure patients by using the Six Sigma method (Ettinger, 2001; Simmons, 2002).

\section{Toyota Production System}

The Toyota Production System (TPS), also referred to as Lean Production System (Womack et al., 1990), has emanated from the Toyota Motor Company as a result of years of continuous efforts to improve on quality and productivity with an emphasis on eliminating all sources of waste in every single area of a process. The TPS has been emulated successfully by several plants around the world. And yet, some companies were not able to reap the promised benefits of adopting such a system. Spear and Bowen (1999) shed the light on what they think contribute to this disparity in implementation results and thus help explain the reason some of those attempts failed in expected performance. They argue that the success of TPS in creating high performance production systems is attributed specifically to four unwritten rules and not to the specific generic TPS tools per se. The four unwritten rules, dubbed by the authors as the DNA of TPS, "guide the design, operation, and improvement of every activity, connection, and pathway for every product and service. The rules are as follows:" (Spear and Bowen, 1999, p. 98)

- Rule 1: All work shall be highly specified as to content, sequence, timing, and outcome.

- Rule 2: Every customer-supplier connection must be direct, and there must be an unambiguous yes-or-no way to send requests and receive responses.

- Rule 3: The pathway for every product and service must be simple and direct. 
- Rule 4: Any improvement must be made in accordance with the scientific method, under the guidance of a teacher, at the lowest possible level in the organization.

Rather than copying the tools, it is through replicating the DNA of TPS as prescribed by the aforementioned four rules that companies may achieve the full benefits and desired performance results of such a system. Spear (2005) provided a detailed discussion on the 4 rules as they apply to process improvement in the health care environment using empirical examples from the Pittsburgh Regional Health Initiative. He stated "The changes I've described at West Penn were individually small changes, but taken together they led to marked improvement in the presurgical unit's performance." (p. 85). Spear concluded that the TPS can be applied in health care, but in order to realize its full potential and institutionalize it, hospital management will need to use TPS principles in their own work.

Ghosh and Sobek (2006) contend that the highly acclaimed success of TPS has been mostly confined to manufacturing settings and not much has been reported on its applicability beyond manufacturing, such as in the health care industry for example. In their paper, they tested the applicability of the first three general rules as introduced by Spear and Bowen (1999) for the design of high performing operations in a health care setting. They conducted their experiment at a small sized hospital. Based on the Spear and Bowen study, the authors decomposed work processes into activity, connection, and pathway, then studied each at length over the course of a about a year. Their study did indicate that appropriate application of the three TPS design rules in that setting did induce improved performance of hospital work processes, thereby extending the applicability of the Spear and Bowen suggested DNA rules beyond the manufacturing context. The results highlighted the need to relate deficient operational problems with flawed work routine; any flaw can be usually attributed to an ill-defined specified activity, unclear 
connections, or complex pathways. Once the root cause is identified, remedial actions could be taken to redesign and improve on the work process. Shah et al. (2008) conducted a long-term case study at the Minneapolis Heart Institute for a patient supply chain. They provided detailed evidence of lean principles for each of the four rules and concluded "the implications from the case study results clearly suggest that lean principles can be successfully used in a health care service process." (p. 778).

Health care organizations must develop innovative processes to address patient care, decision-making, communication channels, and technological changes. Collins and Muthusamy (2007) argue that "TPS can be a powerful intervention technique, even in industries unaccustomed to advanced production techniques such as the health care industry. Because the health care industry is under enormous pressure to reduce costs, increase reliability and quality, and enhance organizational effectiveness, TPS-like interventions are significant to health care organizations" (p. 41).

\section{The A3 Method}

The A3 method was developed by Sobek and Jimmerson (2004) through a grant sponsored by the National Science Foundation. The A3 method is based on the TPS and adapts two problem solving tools used by Toyota: Value-Stream Mapping and the Problem-Solving A3 Report.

Value-Stream Mapping is a tool that identifies where value is added and not added in a process. Value-Stream Maps represent the flow of people, materials and information in the process and includes management decisions and supporting information systems that support the process. They can be used for manufacturing or service organizations as well as the supply chain 
(Rother \& Shook, 1999). Examples of Value-Stream Mapping applications in health care can be found in Endsley et al. (2006) and Lummus et al. (2006)

The Problem-Solving A3 Report utilizes one side of an A3 sheet of paper (11 inches by 17 inches) in landscape orientation. The left-hand side (LHS) is used to show the current process while the right-hand side (RHS) shows the improved process (Sobek and Jimmerson, 2004; Jimmerson, 2007). The LHS is comprised of the following steps:

1. Issue: select a process to observe that has variability in its outcomes, where patient satisfaction could be improved or costs can be reduced. Ask the question "What is the Issue through the eyes of the customer/patient?"

2. Background: develop a clear understanding of how the process interacts within the department and the history of the process. Ask when/where/how often does the problem occur? and objectively collect data so you can measure the Issue.

3. Current Condition: create a simple sketch of the current condition by using a set of standard or customized drawing symbols. In the sketch use storm clouds to highlight problems and within the storm cloud state the specific problem. The Current Condition should always be observed directly and an observation worksheet can be used to record the different activities in the process. Validate the Current Condition by getting staff input on the accuracy of the sketch.

4. Problem Analysis: list the problems identified in the Current Condition (the storm clouds) and for each problem ask Why? five times to determine the root cause of the problem.

Once the current state of the process is understood and a root cause is identified the RHS of the A3 Problem Solving Report is used to show the improved process. The RHS is comprised of the following steps: 
5. Target Condition: draw a simple diagram showing a better way to do the work and highlight the improvements with fluffy clouds. Keep the improvement low cost and if possible create measurable targets for each improvement.

6. Countermeasures: identify the changes that must be made to the Current Condition in order to achieve the Target Condition. Countermeasures eliminate or convert storm clouds to fluffy clouds.

7. Implementation Plan: for each of the countermeasures identify what needs to be done, who will be responsible for getting it done, when it should be completed and what the expected outcome should be.

8. Cost/Benefit: a cost/benefit analysis of the Implementation Plan is necessary in order to justify the process change. Cost is the expense incurred to implement the plan and benefits include both the dollar savings and the improvement in quality.

9. Test: details on how you might test your Implementation Plan prior to full implementation. The Test should determine the effectiveness of the Implementation Plan and it provides an opportunity to make adjustments prior to full implementation.

10. Follow-Up: is conducted in order to determine if your Implementation Plan has been accepted and is now the new way to do the work. The Follow-Up should include the person responsible, the measure or test to be used, and when the Follow-Up will be conducted. The objective of the A3 method is to create the IDEAL health care environment. Jimmerson et al. (2005) adapted the notion of IDEAL from Spear and Bowen (1999) as follows: Exactly what the patient needs, defect free; One by one, customized to each individual patient; On demand, exactly as requested; Immediate response to problems or changes; No waste; Safe for patients, staff, and clinicians: physically, emotionally, and professionally. Current conditions 
that are not IDEAL are identified as storm clouds in Step 3 of the Problem-Solving A3 Report. Anything less than IDEAL is considered waste.

In October, 2002 a pilot project of the A3 method was initiated at the Community Medical Center in Missoula, Montana and subsequently a 7-week training course was developed for employees (Jimmerson et al., 2005). Employee efforts in implementing the A3 method resulted in "significant, medium-scale improvements across many areas of the hospital" (Jimmerson et al., 2005, p. 251). Many of the implementations required little or no investment and improved employee efficiency by reducing wasted time. Benefits also included reductions in overtime hours and errors, and improvements in patient, employee and physician satisfaction (Jimmerson et al. 2005). For case studies of A3 projects see Sobek and Jimmerson (2004), Jimmerson et al. (2005), Inman (2006), and Jimmerson (2007).

The positive reported preliminary results from the use of the A3 method in a health care setting motivated the inclusion of this tool in the executive MBA (EMBA) course to expose the students to this valuable tool and give them an opportunity to apply it to a real world example within their own organization. And, we could collect feedback on the ease of use of the A3 method, as well as its outcome and performance.

The A3 method was selected over the Six Sigma methodology as the process improvement tool of choice for the students' projects for several reasons: First, the A3 method was designed for the health care environment and therefore was an excellent fit with the customization requirements of the EMBA Program. Second, the A3 method uses basic low-level quality tools that do not require extensive training to learn nor is the A3 method as rigid as Six Sigma. Because of this simplicity, it was felt the A3 method could be deployed by an individual and that they could complete a small project during the course of the semester. Third, many hospital 
processes have a significant amount of subjectivity associated with them and data collection can be problematic. Six Sigma has a strong reliance on quantitative data and it was felt this dependence would limit the project options a student had or even force them to find a project in another department.

\section{The Importance of Teaching Quality Principles for Health Care Related Classes}

Although the names have changed, some type of quality framework has continued to be integrated in Operations Management courses. Courses have evolved from a strict quality control framework to total quality management, to six sigma, to lean six sigma (Goeke and Offodile, 2005; Zimmerman and Weiss, 2005), and now to the Toyota Production System which can be specifically industry-adapted such as the A3 method for problem solving for health care (Jimmerson, 2007). The evolution in the classroom mirrors what has happened in industry where a quality-based framework has become a necessity as all organizations are challenged to compete in a dynamic global environment (Smith and Forgione, 2007; Williams et al., 2004), and specifically in health care where the industry is facing a number of operational challenges.

During the summer of 2008 an EMBA cohort class from the Lifespan Organization in Providence, Rhode Island, enrolled in two concurrent courses: Value Formation through Operations, and Continuous Improvement and Performance Excellence. The EMBA Program was a blended program consisting of ten distance learning classes of 90 minutes each and three face-to-face sessions that were held from 9:00 am to 5:00 pm, with breaks and an hour for lunch. 


\section{Course Descriptions}

Value Formation is a core Operations Management (OM) course that covers a variety of OM topics in order to provide a foundation in OM principles. Topics covered included operations strategy, process strategy, design of goods and services, lean systems, supply chain management, inventory management, and location and layout strategies. This course was customized for the EMBA Program by including health care video cases from the course text Principles of Operations Management (Heizer and Render, 2008), a lecture on Radio Frequency Identification applications in health care, and health care related articles from academic journals. Students in this course were assigned an individual A3 Project, which also met the customization requirement.

The Continuous Improvement course presented methods for designing, monitoring, and improving business processes with the objective of increasing patient satisfaction and improving organizational performance. Topics included six sigma, product and process design for quality, performance measurement, statistical process control, continuous improvement, benchmarking, process reengineering, problem solving tools and methodology, and organizational performance assessment using the Malcolm Baldrige National Quality Award Criteria. Continuous Improvement was designed specifically for the EMBA Program and was voted for as an elective course by the cohort. Student teams were required to complete a more overarching strategic project.

To avoid redundancy and to time material relevant for the A3 Project the instructors coordinated their syllabi. For example, though total quality management and statistical process control would normally be covered in the Value Formation course, they were deferred to the Continuous Improvement course. And, detailed discussion of the basic quality tools was covered 
earlier in the Continuous Improvement course so the students could apply these tools in their A3 Projects.

\section{A3 Project Objectives and Rationale}

There were two primary objectives associated with incorporating the A3 Projects into the classroom in the current study. The first was to provide the students with a real-world opportunity to immediately apply principles of OM to their work environment. Ahire (2001) provided a detailed description on the integration of classroom learning with the actual application of OM concepts and tools to solve real problems. Over a one year period, students conducted 70 projects to identify a variety of process improvements for local manufacturing and service firms. This experiential learning approach benefited both the students and the client organizations that sponsored the projects. Similar active learning student projects are discussed by Heriot et al. (2008), and Umble et al. (2008). Heriot et al. (2008) concluded "Students gain a far better understanding of POM by applying the many things they have learned than by simply passively absorbing material in a classroom setting." (p. 475). Umble et al. (2008) described and reported on the results of the Edward Jones Challenges that are conducted for a total of six subject area challenges at Baylor University. They concluded that the "projects can be used to generate many positive learning outcomes for students.” (p. 24). It should be noted that the three above referenced papers were based on team-based projects, while the A3 Projects discussed in this paper are individually based.

The second objective was to instill and integrate systems thinking, quality, and process improvement into the student's skill set. Atwater and Pittman (2006) discussed the importance of instilling systems thinking in managers and presented tools that students can use to develop 
systemic thinking skills. In addition, the authors differentiate between teaching systemic thinking and teaching students about systems. Teaching the former better prepares students for making decisions in a complex adaptive system. Wicks and Visich (2006) described a service walk-through audit project that links an organizations mission statement with competitive priorities and dimensions of service quality. The method incorporates a system's approach to operations and emphasizes the importance of designing, executing, aligning, and integrating the organization's key business processes. Students were required to identify positive and negative aspects of the service and identify improvements for the negatives. Surveys of the students found the approach to be an effective learning tool that added an element of realism to the course.

\section{A3 Project and Requirements}

The A3 Projects were kicked off during the first face-to-face meeting (the $2^{\text {nd }}$ class) through a presentation that covered fundamental quality principles, a brief introduction to the basic tools of quality, the steps required to complete the left and right-hand sides of the A3 Problem Solving Report, the four rules in use, and the seven mudas of health care. In addition, the rationale behind the A3 Projects was explained. As part of their course materials, each student was provided a copy of the workbook A3 Problem Solving for Health care (Jimmerson, 2007). The workbook contains an observation worksheet (process chart) to record details about the valueadding and non-valuing-adding activities that make up a process. We modified the observation worksheet by adding a symbol for storage from Heizer and Render (2008). The modified observation sheet included operation, transportation, inspection, clarification, delay, interruption, locating, and storage. An electronic version was posted on the course BlackBoard site and can 
be obtained from the first author. In order to motivate the students, it was announced that during the final project presentations the class would vote to select an outstanding project and two honorable mention projects.

At the mid-semester face-to-face class each student was required to make a 5 minute oral presentation on the current status of their Project. They also submitted a summary report with the objective being a completed left-hand side A3 Problem Solving Report. During the final class period (the third face-to-face) students submitted a project report which included their A3 Problem Solving Report, a discussion of the ten steps, and any observation sheets and quality tools used. An evaluation form for each project was handed out prior to the presentations to facilitate scoring for the competition and each student had 10 minutes to present their project. The presentations had two objectives. The first objective was to expand the students' knowledge of how the A3 method was applied to improve a diverse group of processes. By sharing the approaches and tools used, the students would have a deeper knowledge of process improvement techniques. The second, and more important objective, was to provide a forum for learning more about the work done by different functional areas within the Lifespan organization. As potential future leaders of Lifespan, the more the students know and understand about the entire organization, the more effective they should be as a leader. After all seventeen A3 Projects had been presented a vote was taken and the top seven projects were selected for Round 2. During Round 2 each finalist was given 20 to 30 minutes to re-present their project and answer in-depth questions presented by their peers. A final vote was then taken to determine the winners who were then announced to the class and given a certificate of recognition. 


\section{Student Perceptions and Propositions}

The A3 Projects were conducted across a wide variety of departments and processes during the course of the semester. A3 Projects ranged from improving an existing process that was either contained in a department or crossed functional boundaries, or to standardize a process that was poorly defined and executed differently in various departments. It was observed that students at a higher job level had more authority to cross functional boundaries with their A3 Projects, while lower job level students worked on projects within their own functional area. The A3 Projects focused on improving patient care and/or patient satisfaction, or improving the efficiency of administrative processes that directly or indirectly impacted patients and employees. Of the seventeen A3 Projects, three students reached Step 9 Test, eleven had a Test scheduled within 3 months, and three did not specify a Test in their A3 Problem Solving Report.

In this paper we do not discuss the specific A3 Projects the students worked on because we do not have permission to do so. Due to the newness of the A3 method our research is focused on student perceptions of the A3 method. For that purpose, we conducted a survey to assess health care professionals' perceptions of the A3 method for problem solving in health care. The survey instrument was organized along four main categories/clusters, namely the seven mudas, the hospital work environment, implementation requirements, and A3 Project outcomes categories. Measurable survey questions utilized a 7-point Likert scale with $1=$ strongly disagree; $4=$ neither agree nor disagree; $7=$ strongly agree. See Appendix A for the survey items. For each cluster of survey items we present the average score, the standard deviation, and the statistical differences (if any) between the items. Because our population standard deviation $\sigma$ is unknown, we follow the recommendation of Ozgur and Strasser (2004) and use the $t$ statistic. For all survey items in a cluster we used Minitab to conduct a paired $t$-test at a $95 \%$ 
confidence level (Minitab, 2000). We report statistical differences between items if the P-value $\leq 0.10$ because: 1 ) the sample size $\mathrm{n}<30$; and 2) in Minitab we selected the alternative not equal in the paired-t options. Increasing the sample size and or using an upper-tailed hypothesis test (greater than) would lower the P-value. Based on the results of the $t$-tests we make propositions that can be used in future research to develop hypothesis and construct models to measure the effectiveness of the A3 method in improving health care operations. We now discuss our survey results for the clusters based on the seven mudas of health care, the hospital work environment, implementation requirements, and A3 Project outcomes.

\section{The Seven Mudas of Health Care}

As mentioned previously Jimmerson (2007) defined seven mudas of health care. Since they are specific to the health care environment, we wanted to know if the A3 method was more applicable to any one muda versus another muda. Sixteen students responded to the following survey item: Please indicate your level of agreement with the following statements regarding the A3 method and the 7 Mudas of Health care. As seen in Table 1, students felt that the A3 method would have the biggest impact on reducing waiting time in hospital processes, followed by motion, confusion and processing. All four of these mudas have the potential to directly impact patient safety and satisfaction, as well as employee satisfaction with clinical and administrative processes. The two lowest rated mudas of over-production and inventory are unlikely to adversely affect patients or employees. Based on these results we propose the following proposition:

Proposition 1 (P1): Health care mudas that directly impact patients and employees will be the focus of A3 method process improvement projects. 
Table 1 The A3 Method and the Seven Mudas ( $n=16)$

\begin{tabular}{|l|l|l|l|}
\hline $\begin{array}{l}\text { The A3 method can } \\
\text { be used to reduce: }\end{array}$ & Avg. & StdDev. & Significantly different from at a level of (P-value): \\
\hline Waiting & 6.1 & 1.4 & $\begin{array}{l}\text { Inventory (0.005); Over-Production (0.007); Defects } \\
(0.055) ; \text { Processing }(0.055)\end{array}$ \\
\hline Motion & 5.9 & 1.2 & $\begin{array}{l}\text { Inventory (0.002); Over-Production (0.007); Defects } \\
(0.076)\end{array}$ \\
\hline Confusion & 5.9 & 1.4 & Inventory (0.016); Over-Production (0.075) \\
\hline Processing & 5.5 & 1.5 & Inventory (0.095) \\
\hline Defects & 5.3 & 1.7 & - \\
\hline Over-Production & 5.1 & 1.6 & - \\
\hline Inventory & 4.9 & 1.6 & - \\
\hline
\end{tabular}

\section{The Hospital Work Environment}

Survey items in this cluster focused on processes within the hospital and satisfaction with those processes. We asked students to respond to the following statement: Please indicate your level of agreement with the following statements regarding the A3 method. The results in Table 2 show that none of the items are significantly different. A $t$-test between administrative processes and employee job satisfaction had a P-value $=0.164$, which was the lowest of the fifteen possible tests. Due to the small sample size, we did not request stratification data such as job function out of concerns that such information would compromise the anonymity of the respondents. However stratification data could provide additional insights into the survey responses as it is expected that certain mudas and processes would be deemed more important to specific groups. For example, physicians and nurses should be more focused on patient care and safety, while employees who work in administrative areas would be more concerned with employee satisfaction. We make two propositions for hospital work environment. 
Proposition 2 (P2): Staff (physicians, nurses, etc.) whose work directly impacts patients will be more focused on improving clinical processes that improve patient safety, care, and satisfaction than staff who work in administrative positions that do not interact directly with patients.

Proposition 3 (P3): Staff whose work directly impacts other employees will be more focused on improving administrative processes that improve efficiency and employee satisfaction than staff who work directly with patients.

Table 2 The A3 Method and the Hospital Work Environment (n=15)

\begin{tabular}{|l|l|l|l|}
\hline The A3 method can be used to: & Avg. & StdDev. & $\begin{array}{l}\text { Significantly different from } \\
\text { at a level of (P-value): }\end{array}$ \\
\hline Improve administrative processes & 5.9 & 1.6 & - \\
\hline $\begin{array}{l}\text { Improve patient satisfaction with clinical } \\
\text { processes }\end{array}$ & 5.8 & 1.7 & - \\
\hline Improve clinical processes & 5.7 & 1.5 & - \\
\hline Improve hospital employee job productivity & 5.7 & 1.6 & - \\
\hline $\begin{array}{l}\text { Improve patient satisfaction with } \\
\text { administrative processes }\end{array}$ & 5.7 & 1.7 & - \\
\hline Improve hospital employee job satisfaction & 5.5 & 1.5 & - \\
\hline
\end{tabular}

\section{Implementation Requirements}

In this cluster we separated the implementation requirements into three areas: level of management support, knowledge of tools, and employee. We asked the following statement for all three areas: Please indicate your level of agreement with the following statements regarding the A3 method and implementation requirements. The results are shown in Table 3.

For management support none of the three management levels are significantly different from one another. However, since we do not know the level of the employee responding to these questions, we cannot make a direct inference of the results. However, managerial support is 
necessary in order to provide an employee with the time to work on an A3 project and we make the following propositions regarding management support.

Proposition 4 (P4): Low level employees require the support of both their immediate supervisor and their department manager to initiate an A3 project.

Proposition 5 (P5): Mid level employees require the support of their immediate supervisor to initiate an A3 project.

Employees need training in process and quality improvement tools so they can use that knowledge to successfully complete an A3 project. For example, before initiating A3 projects at the Community Medical Center in Missoula, Montana employees took a 7-week training course to provide them with the necessary skills (Jimmerson et al., 2005). Knowledge of both the basic concepts of lean systems and the basic tools of quality management were statistically different from knowledge of both advanced tools of quality management and advanced concepts of lean systems. These results support our decision to use the A3 method instead of Six Sigma and leads to the following two propositions.

Proposition 6 (P6): Employees with knowledge of the basic concepts of lean systems and the basic tools of quality management can initiate A3 projects.

Proposition 7 (P7): Implementation of the A3 method will require less training than required for implementation of Six Sigma.

In addition to managerial support and knowledgeable employees, the A3 method requires employees who are motivated to make their projects a success. Results indicated that an employee commitment to process improvement and an empowered employee are both statistically different from a cross-trained employee. This leads to our next propositions. 
Proposition 8 (P8): The more an employee is committed to process improvement, the more successful their A3 project will be.

Proposition 9 (P9): The more empowerment an employee has to make process improvement changes, the more successful their A3 project will be.

Table 3 The A3 Method and Implementation Requirements ( $\mathrm{n}=15)$

\begin{tabular}{|l|l|l|l|}
\hline Implementation of the A3 method requires: & Avg. & StdDev. & $\begin{array}{l}\text { Significantly different } \\
\text { from at a level of (P- } \\
\text { value): }\end{array}$ \\
\hline Management Support & & & \\
\hline Mid-level management support & 6.3 & 1.1 & - \\
\hline Immediate supervisor support & 6.2 & 1.2 & - \\
\hline Top management support & 5.9 & 1.8 & - \\
\hline Knowledge of Tools & & & \\
\hline Knowledge of the basic concepts of lean systems & 5.7 & 1.2 & $\begin{array}{l}\text { Advanced lean }(0.006) ; \\
\text { Advanced quality (0.013) }\end{array}$ \\
\hline $\begin{array}{l}\text { Knowledge of the basic tools of quality } \\
\text { management }\end{array}$ & 5.4 & 0.8 & $\begin{array}{l}\text { Advanced lean }(0.027) ; \\
\text { Advanced quality }(0.072)\end{array}$ \\
\hline $\begin{array}{l}\text { Knowledge of advanced tools of quality } \\
\text { management }\end{array}$ & 4.9 & 1.3 & - \\
\hline Knowledge of advanced concepts of lean systems & 4.7 & 1.2 & - \\
\hline Employee & & & - \\
\hline $\begin{array}{l}\text { An employee commitment to process } \\
\text { improvement }\end{array}$ & 6.1 & 0.9 & $\begin{array}{l}\text { Cross-trained employee } \\
(0.068)\end{array}$ \\
\hline An empowered employee & 6.0 & 1.1 & $\begin{array}{l}\text { Cross-trained employee } \\
(0.045)\end{array}$ \\
\hline A cross-trained employee & 5.3 & 1.2 & \\
\hline
\end{tabular}

\section{A3 Project Outcomes}

The objective of this cluster was to determine the learning outcomes from the A3 Projects and we asked the following question: Please indicate your level of agreement with the following statements regarding your A3 Project and Presentation. The overall high average scores shown in Table 4 indicate that the inclusion of the A3 Projects as part of the course was effective in creating active learning. Organizational learning was achieved as the students were able to 
actually apply the skills they were taught in the classroom to their jobs, which in turn added value to the Lifespan organization. Interestingly, the use of a competition to motivate the students had the lowest score, the highest standard deviation, and was significantly different from all the other items. These results can be interpreted in two ways. Either the student was highly motivated on his or her own and did not need a competition for motivation or the student was not interested in being part of the competition. While this result is inconclusive, the competition facilitated the identification of the seven best projects that were then discussed in greater detail by the class. And, it was during this second round that organizational learning and value to both the students and Lifespan was reinforced. Some student responses to the openended question What were some positive aspects of your A3 Project? were "Good way to apply knowledge gained.," "Learning from my other cohort's presentations,." and "It allowed a visual connection to be made regarding the impact on financials, employees and patients." From this discussion we make the following proposition:

Proposition 10 (P10): The implementation of the A3 method for Problem Solving as a class requirement facilitated active learning. 
Table 4 The A3 Method and Project Outcomes (n=16)

\begin{tabular}{|l|l|l|l|}
\hline & Avg. & StdDev. & $\begin{array}{l}\text { Significantly different from } \\
\text { at a level of (P-value): }\end{array}$ \\
\hline $\begin{array}{l}\text { The A3 Project Presentations provided a forum } \\
\text { for organizational learning }\end{array}$ & 6.3 & 0.8 & $\begin{array}{l}\text { Competition motivator } \\
(0.008)\end{array}$ \\
\hline $\begin{array}{l}\text { My A3 Project provided me with the } \\
\text { opportunity to apply new skills }\end{array}$ & 6.2 & 0.5 & $\begin{array}{l}\text { Competition motivator } \\
(0.034)\end{array}$ \\
\hline $\begin{array}{l}\text { My A3 Project added value to my learning } \\
\text { experience }\end{array}$ & 6.2 & 0.5 & $\begin{array}{l}\text { Competition motivator } \\
(0.034)\end{array}$ \\
\hline $\begin{array}{l}\text { Overall, the A3 Project was an effective } \\
\text { learning experience }\end{array}$ & 6.2 & 0.7 & $\begin{array}{l}\text { Competition motivator } \\
(0.024)\end{array}$ \\
\hline $\begin{array}{l}\text { My A3 Project provided me with the } \\
\text { opportunity to learn new skills }\end{array}$ & 6.1 & 0.8 & $\begin{array}{l}\text { Competition motivator } \\
(0.051)\end{array}$ \\
\hline $\begin{array}{l}\text { The A3 Projects added value to the Lifespan } \\
\text { Organization }\end{array}$ & 6.0 & 0.8 & $\begin{array}{l}\text { Competition motivator } \\
(0.038)\end{array}$ \\
\hline $\begin{array}{l}\text { My A3 Project increased my ability to identify } \\
\text { problems }\end{array}$ & 5.9 & 0.7 & $\begin{array}{l}\text { Competition motivator } \\
(0.085)\end{array}$ \\
\hline $\begin{array}{l}\text { The A3 Project competition was a good } \\
\text { motivator }\end{array}$ & 5.2 & 1.7 & - \\
\hline
\end{tabular}

\section{Additional Questions}

In addition to the Likert scale survey questions, we collected additional information from the survey and from analyzing the student A3 Reports. We asked "Which of the following Tools of Quality was most useful to you in the completion of your A3 Project?" Though prompted to select only one tool, seven students selected more than one tool. Flow charts were the most popular tool, selected eleven times, while cause \& effect diagrams and histograms were selected three times each. We reviewed the A3 Reports and found that fourteen students used one or more observation worksheets, including all seven students whose A3 Project was selected for round 2 of the competition. Flowcharts were actually used by nine students, though time function maps were used by three students while another student used a process decision diagram. Cause \& effect diagrams were used by four students, and a total of fourteen different quality and statistical tools were utilized by students to complete their projects. 
We then asked students the following three open-ended questions: "What were some positive aspects of your A3 Project?”; "What were some negative aspects of your A3 Project?"; and "How could the A3 Project assignment be improved?" Some positive aspects included "It makes you develop a clinical pathway thinking approach," "Allow to apply a system/quality process to everyday activities," and "I found the 5 why process helped me dig down deeper to the root cause of problem. I also found it useful to open and advance dialogue about the process." Negative aspects of the project included time constraints as well as "Gaining compliance with the new process" and "The project was very focused on health care/direct care issues and difficult to match to administrative and relationship-based positions." For improvements to the A3 Projects several students mentioned higher level management support such as "All of these could be business plans to executive management and that should be the targeted outcome" and “A little more explanation, examples of potential projects. Pairing up with a top manager sponsor to work with to do a worthwhile project or teaming of 2 students to work on same project different aspects." One student commented "It is important to stress the narrow scope of these projects." In addition, the A3 Projects were beneficial in instilling quality thinking in both the students and in their colleagues they worked with. Fourteen students indicated they discussed their project with colleagues who were also interested in the projects and eight of the fourteen received assistance from their colleagues.

\section{Conclusions}

In this study we have described the A3 method, discussed why and how we incorporated this rather new tool into an EMBA course for students from a large health care organization, and presented the results of a survey of the students' perceptions of using the A3 method. Currently, 
this is the only study we are aware of that reports on user's perceptions of the A3 method. Based on the student presentations, their A3 reports, and the results from the survey we conclude that the A3 method is a useful process improvement tool for the health care environment.

This research has several limitations. First, the survey respondents were students in an EMBA class and they were required to complete their individual projects during the course of a 12-week semester. This shortened time frame to finish a project outside their normal job responsibilities, while taking 2 graduate courses, limited the amount of time students could devote to their project. In addition, the structure of the course (ten distance learning sessions and only two face-to-face meeting after the projects were introduced) did not allow much time for the instructor to coach the students on their projects. The shortened time and absence of instructor meetings could have had a negative impact on the project outcomes and potentially on student perceptions of the A3 method as well. Four students mentioned time constraints as a negative aspect of their A3 Project including "Very time consuming." and "It was tough to learn how to do one and actually then do one in the time frame of the semester but it was worth it." A second limitation is that the students were not provided with a formal training program to provide them with an extensive background and skills necessary to complete an A3 project. As mentioned previously, employees at the Community Medical Center in Missoula, Montana took a 7-week training course to prepare them for A3 projects. During the training period they worked on an A3 project in their departments and had access to the instructors for advice (Jimmerson et al., 2005). While our students were introduced to the A3 method and exposed to a variety of lean and quality tools, we did not conduct a formal step-by-step training program for the A3 method. We hypothesize that student perceptions of the A3 method would be higher if they had been formally trained in the A3 method while they were working on their projects. A final limitation 
is the small sample size of 15 or 16 used in the statistical analysis, which impacts the normality assumption and reduces the power of the paired $t$-test. The small sample size also limited the number and types of projects the students worked on. It is possible that project selection influenced student perceptions, which the propositions are based on. For example, none of the projects focused on inventory control and Inventory was the lowest ranked muda in Table 1.

Our research has several implications for both practitioners and academicians. For practitioners we have provided a discussion of the A3 Method for Problem Solving in Health care and shown that $\mathrm{A} 3$ based projects can be initiated by individual employees with low levels of training in a short period of time (less than three months). Employees should be able to get their colleagues interested in their projects and receive assistance from them as well. Unlike Six Sigma, the A3 method utilizes basic quality and lean tools and therefore employees do not need a high level of quantitative skills to initiate projects. One student mentioned the following positive aspect of their A3 Project: "It allowed me to take on a new challenge in terms of my work team and help develop a new policy above the level of my current work assignment.", indicating the A3 method can also be used for job enlargement. In addition, we believe the A3 method can be utilized in any industry to make significant improvements in small to medium scale processes. For academicians we have discussed how the A3 method can be used as a framework for student projects in the health care environment. Future research could test or modify the ten propositions we have made or it can focus on the impact of the A3 method to improve different types of processes, for example administrative versus clinical. Given the difficulties in measuring patient care, longitudinal studies could focus of the impact of the A3 method to improve patient satisfaction and outcomes. The long-term impact on reducing cost, increasing profit or building competitive advantage could also be studied. Research could also investigate the application of 
the A3 method in other service industries, including for-profit, non-profit and government, as well as the manufacturing and logistics industries.

\section{References}

Abernethy, M. and A. Lillis, "Interdependencies in Organization Design: A Test in Hospitals," Journal of Accounting Management Research, 13 (1), 107-129, 2001.

Ahire, S., "Linking Operations Management Students Directly to the Real World," Interfaces, 31 (5), 104-120, 2001.

Atwater, J.B and P.H. Pittman, "Facilitating Systemic Thinking in Business Classes," Decision Sciences Journal of Innovative Education, 4 (2), 273-292, 2006.

Black, K. and L. Revere, "Six Sigma Arises From the Ashes of TQM With a Twist," International Journal of Health care Quality Assurance, 19 (3), 259-266, 2006.

Bliemel, M. and K. Hassanein, "E-health: Applying Business Process Reengineering Principles to Healthcare in Canada," International Journal of Electronic Business, 2 (6), 625-643, 2004.

Bouwens, J. and M. Abernethy, "The Consequences of Customization on Management Accounting System Design," Accounting, Organizations and Society, 25 (3), 221-241, 2000.

Business Wire, "Medical Errors Cost U.S. \$8.8 Billion, Result in 238,337 Potentially Preventable Deaths, According to HealthGrades Study," Business Wire, April 8, 2008.

Carman, J., S. Shortell, R. Foster and E. Hughes, "Keys For Successful Implementation of Total Quality Management in Hospitals," Healthcare Management Review, 21 (1), 48-61, 1996.

Collins, K.F. and S.K. Muthusamy, "Applying the Toyota Production System to a Healthcare Organization: A Case Study on a Rural Community HealthCare Provider," The Quality Management Journal, 14 (4), 41-52, 2007.

Crane, J. and F. Crane, "Preventing Medication Errors in Hospitals Through a Systems Approach and Technological Innovation: A Prescription for 2010," Hospital Topics, 84 (4), 3-8, 2006.

Endsley, S., M.K. Magill and M.M. Godfrey, "Creating a Lean Practice," Family Practice Management, 13 (4), 34-38, 2006.

Ettinger, W., “Six Sigma Adapting GE's Lesson to Healthcare,” Trustee, 54 (8), 10-16, 2001. 
Feng, Q.M. and C.M. Manuel, "Under the Knife: A National Survey of Six Sigma Programs in US Health care Organizations," International Journal of Healthcare Quality Assurance, 21 (6), 535-547, 2008.

Ghosh, M. and D. Sobek, "A Test of the Design Rules in Healthcare," Proceedings of the Industrial Engineering Research Conference, Orlando, FL, USA, 2006.

Goeke, R. and F. Offodile, "Forecasting Management Philosophy Life Cycles: A Comparative Study of Six Sigma and TQM," The Quality Management Journal, 12 (2), 34-47, 2005.

Heizer, J. and B. Render, "Principles of Operations Management," $7^{\text {th }}$ edition, Pearson Prentice Hall, Upper Saddle River, NJ, USA, 2008.

Heriot, K.C., R. Cook, R.C. Jones and L. Simpson, “The Use of Student Consulting Projects as an Active Learning Pedagogy: A Case Study in a Production/Operations Management Course," Decision Sciences Journal of Innovative Education, 6 (2), 463-481, 2008.

Inman, W. "Drawing up the Best Remedy," Industrial Engineer, 38 (4), 48-49, 2006.

Jagsi, R., B. Kitch, D. Weinstein, E. Campbell, M. Hutter and J. Weissman, "Residents Report on Adverse Events and Their Causes," Archives of Internal Medicine, 165, Dec. 12/26, 26072613, 2005. Downloaded from www.archinternmed.com on October 8, 2008.

Jimmerson, C., "A3 Problem Solving for Healthcare," Healthcare Performance Press, New York, USA, 2007.

Jimmerson, C., D. Weber and D.S. Sobek, "Reducing Waste and Errors: Piloting Lean Principles at Intermountain Healthcare," Journal on Quality and Patient Safety, 31 (5), 249-257, 2005.

Kohn, L., J. Corrigan and M. Donaldson, editors, To Err is Human: Building a Safety Health System, Committee on Quality Healthcare in America, Institute of Medicine, National Academic Press, Washington, D.C., 2000.

Lazarus, I.R. and K. Butler, "The Promise of Six Sigma," Managed Healthcare Executive, 11 (9), 22-26, 2001.

Lazarus, I.R. and B. Stamps, "The Promise of Six Sigma," Managed Healthcare Executive, 12 (1), 27-30, 2002.

Lummus, R.R., R.J. Vokurka and B. Rodeghiero, "Improving Quality through Value Stream Mapping: A Case Study of a Physician's Clinic," Total Quality Management, 17 (8), 1063$1075,2006$.

Martin, W.F., "Quality Models: Selecting the Best Model to Deliver Results," The Physician Executive, 33 (3), 24-31, 2007. 
Menachemi, N., J. Burkhardt, R. Shewchuk, D. Burke and R. Brooks, "Hospital Information Technology and Positive Financial Performance: A Different Approach to Finding an ROI," Journal of Health care Management, 51 (1), 40-60, 2006.

Minitab, Release 13 for Windows, Minitab, Inc., 3081 Enterprise Drive, State College, PA, 2000.

Naman, J. and D. Slevin, "Entrepreneurship and the Concept of Fit: A Model and Empirical Tests," Strategic Management Journal, 14 (2), 137-154, 1993.

Nonthaleerak, P. and L.C. Hendry, "Six Sigma: Literature Review and Key Future Research Areas," International Journal of Six Sigma and Competitive Advantage, 2 (2), 105-138, 2006.

Ozgur, C. and S.E. Strasser, "A Study of the Statistical Inference Criteria: Can We Agree on When to use Z Versus t?" Decision Sciences Journal of Innovative Education, 2 (2), 177192, 2004.

Relman, A., "The Institute of Medicine Report on the Quality of Healthcare - Crossing the Quality Chasm: A New Health System for the $21^{\text {st }}$ Century," The New England Journal of Medicine, 345 (9), 702-704, 2001.

Rother, M. and J. Shook, "Learning to See," The Lean Enterprise Institute, Inc., Brookline, MA, 1999.

Sehwail, L. and C. DeYong, "Six Sigma in Healthcare," International Journal of Healthcare Quality Assurance, 16 (6), 1-5, 2003.

Shah, R., S.M. Goldstein, B.T. Unger and T.D. Henry, "Explaining Anomalous High Performance in a Health Care Supply Chain," Decision Science, 39 (4), 759-789, 2008.

Simmons, J.C., "Using Six Sigma to Make a Difference in Healthcare Quality," Quality Letter for Health care Leaders, 14 (4), 2-10, 2002.

Slater, S. and E. Olson, "Strategy Type and Performance: The Influence of Sales Force Management," Strategic Management Journal, 21 (8), 813-828, 2000.

Smith, P. and D. Forgione, "Global Outsourcing of Healthcare: A Medical Tourism Decision Model," Journal of Information Technology Case and Application Research, 9 (3), 19-30, 2007.

Sobek, D. and C. Jimmerson, "A3 Reports: Tool for Process Improvement," Proceedings of the Industrial Engineering Research Conference, Houston, TX, USA, 2004.

Spear, S., "Fixing Healthcare from the Inside, Today," Harvard Business Review, 83 (9), 78-91, 2005. 
Spear, S. and H.K. Bowen, "Decoding the DNA of the Toyota Production System," Harvard Business Review, 77 (5), 97-106, 1999.

Tang, P. and D. Lansky, "The Missing Link: Bridging the Patient-Provider Health Information Gap," Health Affairs, 24 (5), 1290-1296, 2005.

Umble, E.J., M. Umble and K. Artz, "Enhancing Undergraduates' Capabilities Through TeamBased Competitions: The Edward Jones Challenge," Decision Sciences Journal of Innovative Education, 6 (1), 1-27, 2008.

Wicks, A.M. and J.K. Visich, "The IDEAL Service Transaction Analysis Approach for Projects in Operations Management Courses," International Journal of Information and Operations Management Education, 1 (4), 327-342, 2006.

Wicks, A.M., J.K. Visich and S. Li, "Radio Frequency Identification Applications in Healthcare," International Journal of Healthcare Technology and Management, 7 (6), 522540, 2006.

Williams, R., T. van der Wiele and J. van Iwaarden, "TQM: Why it Will Again Become a Top Management Issue," The International Journal of Quality \& Reliability Management, 21 (6/7), 603-611, 2004.

Womack, J.P., D.T. Jones and D. Roos, "The Machine that Changed the World," Rawson Associates, New York, NY, USA, 1990.

Zimmerman, J. and J. Weiss, “Six Sigma's Seven Deadly Sins,” Quality, 44 (1), 62-67, 2005. 


\section{Appendix A}

\section{Health Care Professionals Perceptions of the A3 Method for Problem Solving in Health Care}

Appendix A on page 138 of the workbook A3 Problem Solving for Healthcare by Cindy Jimmerson lists the following 7 Mudas of Health Care.

Confusion: people doing the work are not confident about the best way to perform tasks.

Motion: movement of people that does not add value.

Waiting: idle time created when people, information, equipment, or materials are not at hand.

Processing: activities that do not add value from the patient customers perspective.

Inventory: more materials on hand than are required to do the work.

Defects: work that contains errors or lacks something of value.

Over-production: redundant work.

Please indicate your level of agreement with the following statements regarding the A3 method and the 7 Mudas of Health care.

Scale: 1 = strongly disagree; 4 = neither agree nor disagree; 7 = strongly agree

\begin{tabular}{|c|c|c|c|c|c|c|c|}
\hline The A3 method can be used to reduce: & \multicolumn{3}{|c|}{$\begin{array}{l}\text { Strongly } \\
\text { disagree }\end{array}$} & & \multicolumn{3}{|c|}{$\begin{array}{r}\text { Strongly } \\
\text { agree }\end{array}$} \\
\hline Confusion & 1 & 2 & 3 & 4 & 5 & 6 & 7 \\
\hline Motion & 1 & 2 & 3 & 4 & 5 & 6 & 7 \\
\hline Waiting & 1 & 2 & 3 & 4 & 5 & 6 & 7 \\
\hline Processing & 1 & 2 & 3 & 4 & 5 & 6 & 7 \\
\hline Inventory & 1 & 2 & 3 & 4 & 5 & 6 & 7 \\
\hline Defects & 1 & 2 & 3 & 4 & 5 & 6 & 7 \\
\hline Over-production & 1 & 2 & 3 & 4 & 5 & 6 & 7 \\
\hline
\end{tabular}

Please indicate your level of agreement with the following statements regarding the A3 method.

Scale: 1 = strongly disagree; $4=$ neither agree nor disagree; $7=$ strongly agree

\begin{tabular}{|c|c|c|c|c|c|c|c|}
\hline The A3 method can be used to: & \multicolumn{3}{|c|}{$\begin{array}{l}\text { Strongly } \\
\text { disagree }\end{array}$} & & \multicolumn{3}{|c|}{$\begin{array}{r}\text { Strongly } \\
\text { agree }\end{array}$} \\
\hline Improve clinical processes & 1 & 2 & 3 & 4 & 5 & 6 & 7 \\
\hline Improve patient satisfaction with clinical processes & 1 & 2 & 3 & 4 & 5 & 6 & 7 \\
\hline Improve administrative processes & 1 & 2 & 3 & 4 & 5 & 6 & 7 \\
\hline Improve patient satisfaction with administrative processes & 1 & 2 & 3 & 4 & 5 & 6 & 7 \\
\hline Improve hospital employee job productivity & 1 & 2 & 3 & 4 & 5 & 6 & 7 \\
\hline Improve hospital employee job satisfaction & 1 & 2 & 3 & 4 & 5 & 6 & 7 \\
\hline
\end{tabular}

Please indicate your level of agreement with the following statements regarding the A3 method.

Scale: 1 = strongly disagree; 4 = neither agree nor disagree; $7=$ strongly agree

\begin{tabular}{|c|c|c|c|c|c|c|c|}
\hline Implementation of the $\mathrm{A} 3$ method requires: & & & & & & & \\
\hline Top management support & 1 & 2 & 3 & 4 & 5 & 6 & 7 \\
\hline Mid-level management support & 1 & 2 & 3 & 4 & 5 & 6 & 7 \\
\hline Immediate supervisor support & 1 & 2 & 3 & 4 & 5 & 6 & 7 \\
\hline Knowledge of the basic concepts of lean systems & 1 & 2 & 3 & 4 & 5 & 6 & 7 \\
\hline Knowledge of advanced concepts of lean systems & 1 & 2 & 3 & 4 & 5 & 6 & 7 \\
\hline Knowledge of the basic tools of quality management & 1 & 2 & 3 & 4 & 5 & 6 & 7 \\
\hline Knowledge of advanced tools of quality management & 1 & 2 & 3 & 4 & 5 & 6 & 7 \\
\hline An employee commitment to process improvement & 1 & 2 & 3 & 4 & 5 & 6 & 7 \\
\hline An empowered employee & 1 & 2 & 3 & 4 & 5 & 6 & 7 \\
\hline A cross-trained employee & 1 & 2 & 3 & 4 & 5 & 6 & 7 \\
\hline
\end{tabular}


Please indicate your level of agreement with the following statements regarding your A3 Project and Presentation Scale: $1=$ strongly disagree; $4=$ neither agree nor disagree; $7=$ strongly agree

\begin{tabular}{|c|c|c|c|c|c|c|c|}
\hline & \multicolumn{3}{|c|}{$\begin{array}{l}\text { Strongly } \\
\text { disagree }\end{array}$} & & \multicolumn{3}{|c|}{$\begin{array}{r}\text { Strongly } \\
\text { agree }\end{array}$} \\
\hline My A3 Project increased my ability to identify problems & 1 & 2 & 3 & 4 & 5 & 6 & 7 \\
\hline My A3 Project provided me with the opportunity to learn new skills & 1 & 2 & 3 & 4 & 5 & 6 & 7 \\
\hline My A3 Project provided me with the opportunity to apply new skills & 1 & 2 & 3 & 4 & 5 & 6 & 7 \\
\hline My A3 Project added value to my learning experience & 1 & 2 & 3 & 4 & 5 & 6 & 7 \\
\hline The A3 Project competition was a good motivator & 1 & 2 & 3 & 4 & 5 & 6 & 7 \\
\hline The A3 Project Presentations provided a forum for organizational learning & 1 & 2 & 3 & 4 & 5 & 6 & 7 \\
\hline The A3 Projects added value to the Lifespan Organization & 1 & 2 & 3 & 4 & 5 & 6 & 7 \\
\hline Overall, the A3 Project was an effective learning experience & 1 & 2 & 3 & 4 & 5 & 6 & 7 \\
\hline
\end{tabular}

Which of the following Tools of Quality was most useful to you in the completion of your A3 Project? (select only one tool)

Check Sheet

_ Scatter Diagram

_ Cause and Effect Diagram

Pareto Chart

__ Flow Chart

Histogram

_ Statistical Process Control

What were some positive aspects of your A3 Project?

What were some negative aspects of your A3 Project?

How could the A3 Project assignment be improved?

Were you able to implement your process improvement idea? Yes / No

Did you discuss your A3 Project with your co-workers? Yes / No

If Yes, were they interested in your project Yes / No and did they provide assistance Yes / No 